\title{
Traumatic Bilateral Scaphoid Fracture-A Case Report
}

\author{
Tanvi Umashree, Sumit Kumar Jain* and Pavan Sarin \\ Orthopaedics Department, North Delhi Municipal Corporation Medical College \& Hindu Rao Hospital, Delhi, India
}

${ }^{*}$ Corresponding author: Sumit Kumar Jain, MBBS, MRCS, MS (Ortho), MCh, Orthopaedics Department, NDMC Medical College \& Hindu Rao Hospital, Delhi, India, E-mail: jainsumit24@gmail.com

Received date: December 02, 2017; Accepted date: January 08, 2018; Published date: January 12, 2018

Citation: Umashree T, Jain SK, Sarin P (2018) Traumatic Bilateral Scaphoid Fracture-A Case Report. J Clin Exp Orthop Vol 4, No 1: 51.

Copyright: (02018 Umashree T, et al. This is an open-access article distributed under the terms of the Creative Commons Attribution License, which permits unrestricted use, distribution, and reproduction in any medium, provided the original author and source are credited.

\section{Abstract}

Introduction: The largest carpal bone, the scaphoid, is the most commonly injured bone in the wrist joint. While unilateral scaphoid fractures are quite common, bilateral ones are rarely encountered. Existing literature on traumatic bilateral scaphoid fractures is very limited.

Case report: We came across a young biker, who sustained bilateral, undisplaced, scaphoid waist fractures following a road traffic accident. He was treated conservatively with bilateral thumb spica casts, and recovered fully in about 12 weeks after the injury.

Conclusion: Comprehensive imaging should be done in case of suspected scaphoid fractures, as failure to do so may lead to missed fracture. Although internal fixation reduces healing time, conservative management with thumb spica casts can also successfully treat undisplaced bilateral scaphoid fractures, and the patient can attain full range of motion within a comparable time frame. Surgical management should be favored more in case of displaced/ unstable fractures.

\section{Introduction}

The scaphoid is the largest bone of the proximal carpal row. It serves as a bridge between the proximal and the distal carpal bones and transfers compression loads from the hand to the forearm and has a major role in maintaining carpal stability [1]. The primary mechanism of scaphoid fracture is hyperextension of the wrist beyond $95^{\circ}$, which commonly occurs by a fall onto an outstretched hand $[2,3]$. Forced wrist extension beyond $95^{\circ}$ traps the proximal pole of the scaphoid between the capitate, radius, and palmar capsule, while the distal pole of the scaphoid moves freely [4]. The waist of the scaphoid tends to be the focus of this stress, which leads to fractures at this site in approximately $80 \%$ of cases of Scaphoid fracture $[5,6]$.

The scaphoid is the most commonly injured carpal bone in young male patients [2]. Unilateral fracture of the scaphoid is widely known, however, isolated bilateral fractures of the scaphoid are rare in occurrence. We came across a young biker who fractured both his scaphoid bones during an accident.

\section{Case Report}

A 28 yr old biker presented to our casualty, with pain in both his wrists, following an accident the day before. He was riding his bike, when he struck a vehicle from behind, resulting in forced dorsiflexion of both his wrists. Before presenting to us, he had only taken an analgesic medication to lessen the pain. The physical examination showed a healthy looking young man, in moderate to severe pain, with tenderness in both anatomical snuff boxes. Scaphoid compression test was positive in both wrists. Radiological examination was done. Three views, PA view with ulnar deviation, lateral, and oblique, were taken. No fracture was seen in the PA and lateral views, but oblique view revealed faint fracture lines in both scaphoids (Figures 1-3). A computed tomography scan was done to confirm this finding, to check the configuration and displacement, if any, and to rule out any other injury. The scans showed bilateral, undisplaced scaphoid waist fractures, without any associated injuries.

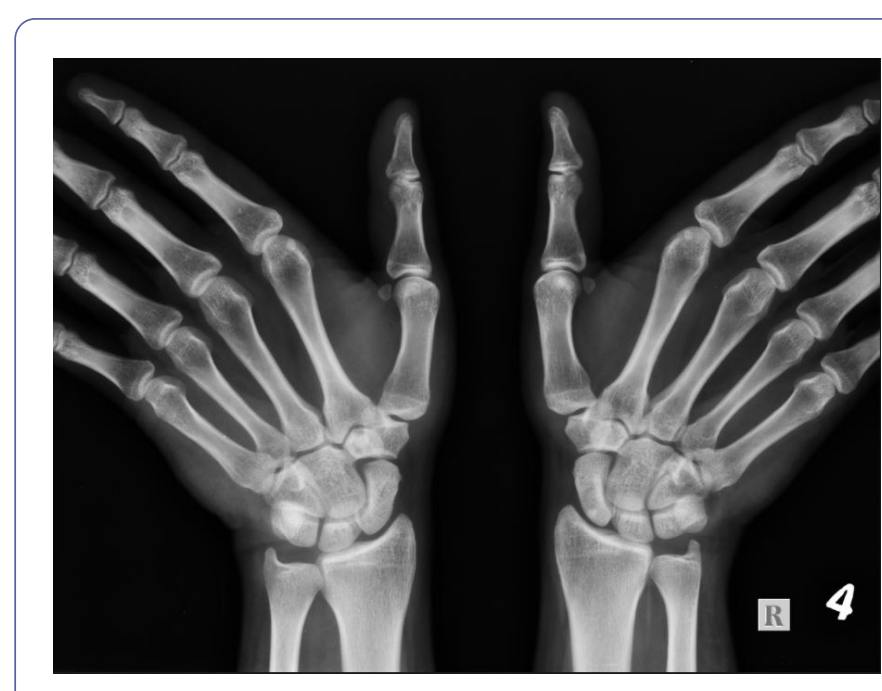

Figure 1: Anteroposterior view with ulnar deviation of both wrist showing no fracture scaphoid. 


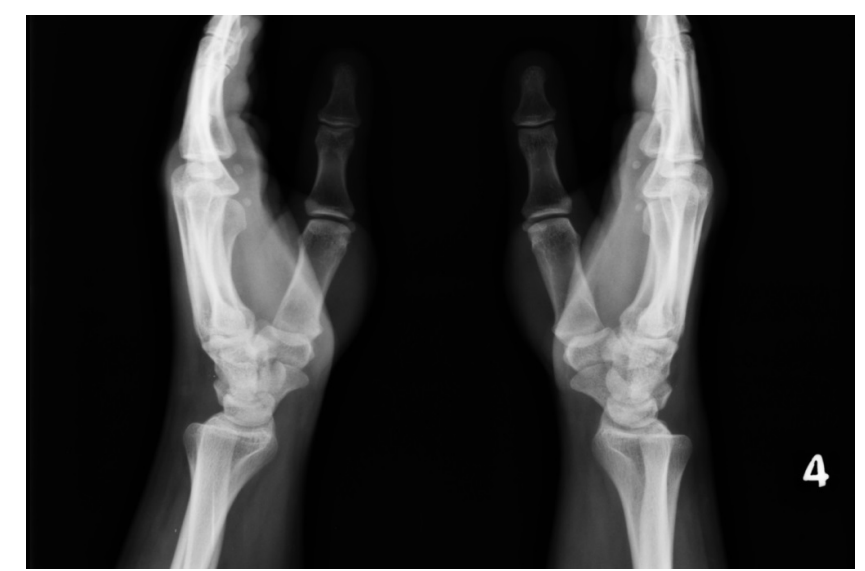

Figure 2: Lateral view of both wrist showing no fracture of scaphoid.

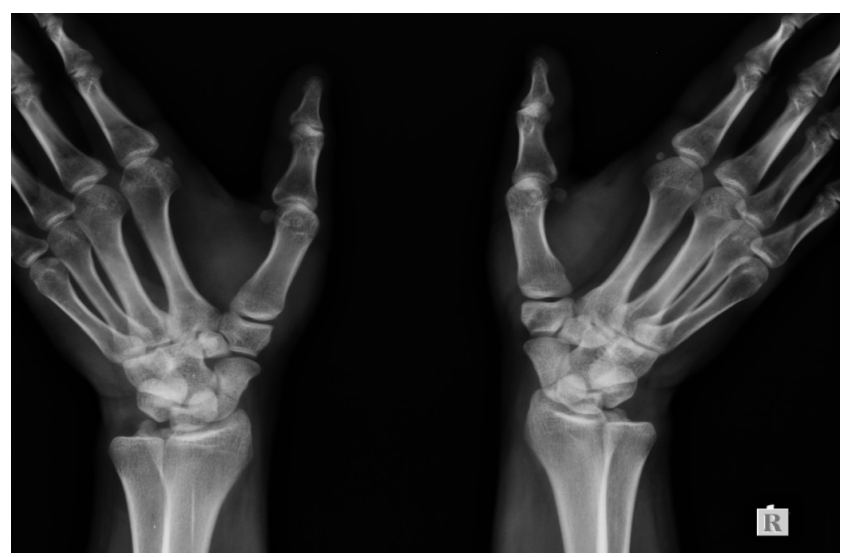

Figure 3: Oblique views of both wrist showing fracture of waist of both scaphoids.

The various methods of treatment available were discussed with the patient: broadly, conservative and surgical. The patient was initially unwilling for bilateral casts, as they would hinder his daily activities, but after discussion regarding the time it will take for the fracture to unite, and surgery and its complications, he decided to go with conservative treatment.

He was given bilateral thumb spica casts. A check X-ray was taken after applying the cast to rule out any displacement of the fracture fragments. On finding that both fractures remained undisplaced, the patient was counseled, sent home, and subsequently followed up after 4 weeks and 8 weeks. A check Xray was done at 4 weeks. The casts were removed at 8 weeks and a check X-ray showed that fracture was healing well (Figure 4). Gentle ranges of motion exercises were started. At 12 weeks of follow-up, the fractures had healed completely (Figure 5) and patient had achieved pain free full range of movements and was back to work.

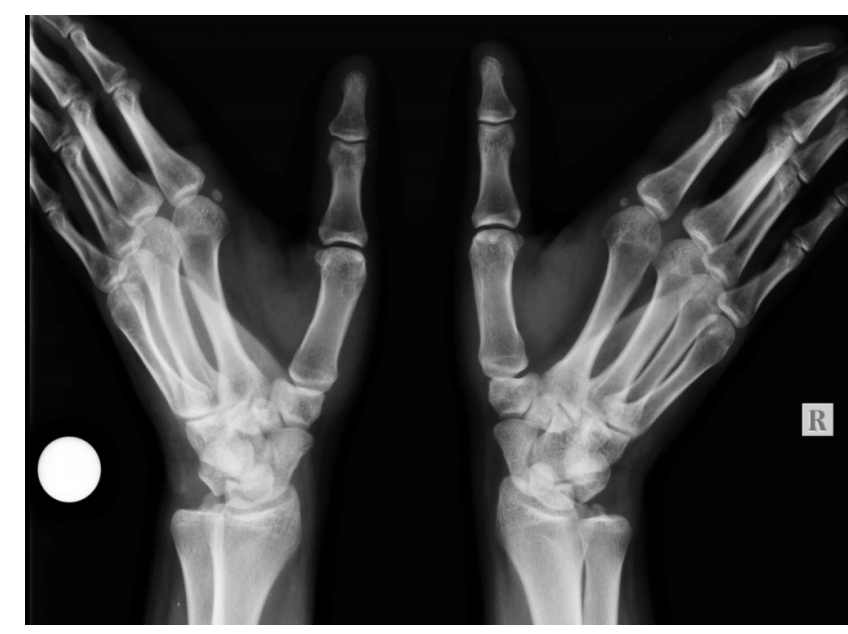

Figure 4: Oblique views of both wrist at 8 weeks showing fractures are healing well.

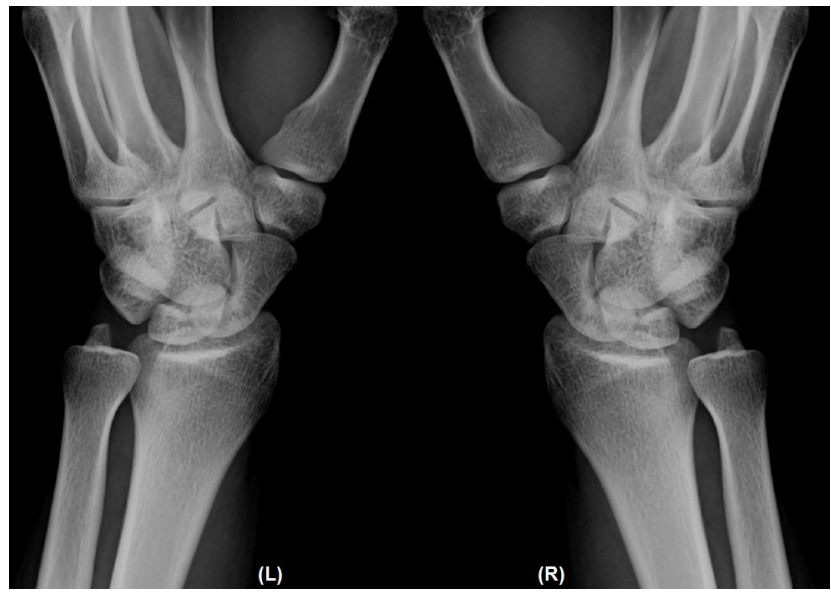

Figure 5: Oblique views at 12 weeks showing that fracture has healed completely.

\section{Discussion}

Scaphoid fractures are the most common of all carpal bone fractures, consisting of $2.4 \%$ of all wrist fractures, in the United States [7]. Bilateral scaphoid fractures, occurring simultaneously, are uncommon, especially if traumatic. They are most often seen as stress fractures in sportspersons and manual workers [8].

In patients with wrist injury, anatomical snuff box tenderness is sensitive but not specific for scaphoid fractures, as it is also found in other conditions. Instead, scaphoid tubercle tenderness, and scaphoid compression test (which we did in this case) are considered more specific to scaphoid fractures [9-11].

X-ray examination of scaphoid fractures is very comprehensive, comprising of at least 4 views- PA, lateral, semipronated oblique, and scaphoid (with the wrist pronated in ulnar deviation and the X-ray beam directed upward, at angle of 25 degrees with the vertical axis). Although, by mistake, we advised 
only three views, we were lucky enough that the fracture could be seen in the oblique view. This is an example of how each view is of importance in scaphoid fractures. Had we not done the oblique view, we could have easily missed the fracture. Scaphoid fracture can be easily missed if all the recommended views are not done. However, the standard guidelines now are to treat a case clinically suggestive of scaphoid fracture as a fracture, even if it is not visible in any of the X-ray views. Such a patient should be followed up after 2-3 weeks of immobilization with an X-ray or a bone scan $[12,13]$.

Conservative treatment is usually done in cases of undisplaced/stable fractures. Our patient was special in that he had bilateral fractures, and thus his concerns and unwillingness for bilateral casts was understandable. However, considering that surgeries are usually reserved for more complicated cases, and after a discussion with the patient on the complications, we came to a consensus: to apply casts. In a study conducted by Saedén, comparing conservative below elbow thumb spica treatment with Herbert screw placement, over a $12 \mathrm{yr}$ follow up, showed that union occurred in both sets of patients, and interestingly, osteoarthritis of scaphotrapezial joint was greater in operated patients [8]. A similar study by Clementson done on nondisplaced or minimally displaced waist fractures showed no difference in grip or pinch strength between the 2 cohorts (conservatively and operatively treated), and in fact, an increased range of motion was noted in the non operative group [14]. Though newer techniques like arthroscopy assisted fixation of scaphoid fractures are now available, there are not enough data yet to compare long term results to standard methods $[15,16]$. Moreover, surgical management is more preferred in unstable and complicated fractures.

Our patient was given bilateral thumb spica casts. Though recent studies have shown that thumb immobilization does not have a significant effect on the outcome of the fracture, and that a Colle's cast may suffice $[17,18]$, we decided to stick to the prescribed guidelines. There is some controversy regarding the angle of the wrist when immobilized. Some authors suggest ulnar deviation, while some suggest 20 degrees of flexion or extension [12]. In a study by Hambridge, it was shown that there is no difference in union in extension or flexion, but wrists immobilized in flexion showed greater restriction in extension after 6 months [19].

After removal of casts 8 weeks later, patient was advised gentle range of motion exercises and eventually, after 12 weeks, he had attained complete union and full range of movement and was back to work.

\section{Conclusion}

Comprehensive imaging should be done in case of suspected scaphoid fractures. At least 4 X-ray views, PA with ulnar deviation, lateral, scaphoid and oblique, must be ordered, and a CT should be done to confirm displacement and other associated bony injuries.

Treatment of scaphoid fractures is controversial. Even though internal fixation reduces healing time, this case shows us that conservative management with thumb spica casts can also successfully treat undisplaced bilateral scaphoid fractures, and the patient can attain full range of motion within a comparable time frame. Surgical management should be favored more in case of displaced/unstable fractures.

\section{Message}

1. All the recommended views of Scaphoid should be done as Scaphoid fracture can be easily missed if all the recommended views are not done.

2. Conservative vs operative treatment is equally effective in undisplaced, stable and uncomplicated scaphoid waist fracture; however, surgical treatment is reserved for displaced, unstable and complicated fractures.

\section{References}

1. Krasin E, Goldwirth M, Gold A, Goodwin DR (2001) Review of the current methods in the diagnosis and treatment of scaphoid fractures. Postgrad Med J 77: 235-237.

2. Louis S, Warwick DJ, Nagayam S (2001) Appley's System of Orthopaedics and Fractures. (8thedn), Anold London, pp. 620-628.

3. Chapman MW (1996) Chapman's Orthopaedic Surgery; Philapdelphia. JB Lipincott Co, 1307-1331.

4. Weber ER, Chao EY (1978) An experimental approach to mechanism of scaphoid waist fractures. J Am Hand Surg 3: 142-148.

5. Borgeskov S, Christiansen B, Kjaer A, Balslev I (1966) Fractures of the carpal bones. Acta Orthop Scand 37: 276-287.

6. Amadio PC, Taleisnik J (1999) Fractures of the carpal bones. In: Amadio PC, Taleisnik J, Editors, Green's Operative Hand Surgery, Oxford, UK, Elsevier, 815.

7. Van Tassel DC, Owens BD, Wolf JM (2010) Incidence, estimates, and demographics of scaphoid fracture in the U.S. population. J Hand Surg Am 35: 1242-1245.

8. Saeden B, Lorkvist H, Ponzer S, Hohlund M (2001) Fractures of the Scaphoid: A prospective randomized 12 year follow up comparing operative and conservative treatment. J Bone Joint Surg 83B: 230-234.

9. Chen SC (1989) The Scaphoid Compression Test. J Hand Surg $\mathrm{Br}$ 14B: 323-325.

10. Freeland $P$ (1989) Scaphoid tubercle tenderness: a better indicator of scaphoid fractures? Arch Emerg Med 6: 46-50.

11. Hankin FM, Smith PA, Braunstein EM (1986) Evaluation of the carpal scaphoid. Am Fam Pract 34: 129-132.

12. Cooney WP, Linscheid RL, Dobyns JH (1996) Fractures and dislocations of the wrist. In: Rockwood CA ,et al. (eds) Fractures in adults. (4thEd), Philadelphia: Lippincott-Raven, pp. 745-767.

13. Sampson SP, Wisch D, Akelman E (1997) Fractures and dislocations of the hand and wrist. In: Dee R, et al. Principles of orthopaedic practice. (2ndEd), New York: McGrawHill, pp. 429-442.

14. Clementson $\mathrm{M}$, Jørgsholm P, Besjakov J, Thomsen $\mathrm{N}, \mathrm{Bj}$ ”'orkman A (2015) Conservative treatment versus arthroscopic-assisted screw fixation of scaphoid waist fractures-a randomized trial with minimum 4-year follow-up. J Hand Surg Am 40: 1341-1348.

15. Whipple TL (1995) Stabilization of the fractured scaphoid under arthroscopic control. Orthop Clin North Am 26: 749-754. 
16. Slade JF, Lozano-Calderón S, Merrell G, Ring D (2008) Arthroscopic-assisted percutaneous reduction and screw fixation of displaced scaphoid fractures. J Hand Surg Eur 33: 350-354.

17. London PS (1961) The broken scaphoid bone. J Bone Joint Surg Br 43B: 237-244.

18. Bohler L, Trohan E, Jahna H (1954) Behandlungsergebnisse von 734 Frischen Einfachen Brüchen des Kahnbeinkörpers der Hand. Reconstr Surg Traumatol 2: 86-111.
19. Hambidge JE, Desai VV, Schranz PJ (1999) Acute fractures of the scaphoid. Treatment by cast immobilisation with the wrist in flexion or extension? J Bone Joint Surg Br 81: 91-92. 